\title{
Comportamento físico da precipitação interna em um povoamento de Eucalyptus
}

\author{
Physical behavior of throughfall in a planting of Eucalyptus \\ José de Oliveira Melo Neto ${ }^{\mathrm{I}}$ Carlos Rogério de Mello"I José Márcio de Mello"II \\ Danielle Vieira Guimarães ${ }^{\mathrm{IV}}$
}

\begin{abstract}
Resumo
A compreensão das características físicas da chuva e sua interação com a paisagem possibilita o desenvolvimentode modelos matemáticos mais condizentes com a realidade além de auxiliar no planejamento eficiente de obras e práticas agrícolas. O objetivo deste estudo foi caracterizar a precipitação interna de um povoamento de Eucalyptus no município de Lavras, Minas Gerais, associado a padrões hidrológicos e potencial erosivo. Para individualização dos eventos de precipitação interna foram adotados os intervalos de 3 e 6 horas entre chuvas. Para cada abordagem foi realizada a classificação do padrão hidrológico da precipitação, incidente e interna, e, associados a estes, as características das chuvas: lâmina precipitada, tempo de duração, energia cinética, intensidades média e máxima, e erosividade. A precipitação interna no povoamento de eucalipto representou $79,2 \%$ da precipitação externa. A precipitação interna mostrouse $36,4 \%$ menos erosiva do que a precipitação externa, na qual o padrão avançado foi identificado como predominante na série analisada em ambas as metodologias de individualização dos eventos.
\end{abstract}

Palavras-chave: Energia cinética da chuva; Interação dossel do eucalipto-precipitação; Padrão da precipitação

\begin{abstract}
The understanding of rainfall physical characteristics and their interaction with the landscape allow the development of more feasible mathematical models to be applied on the planning of agricultural conservation practices. However, only a few studies have tried to characterize the throughfall in planted forests, like eucalyptus plantation. The objective of this study was to characterize the throughfall behavior under Eucalyptus canopy, at Lavras county region, southern Minas Gerais state, relating it to the hydrology pattern and erosive potential of the rainfall. For that, rainfall events were individualized by means of two criteria: 6 and 3 hours between the events, consecutively. For each one of the approaches, both gross precipitation and throughfall were classified in terms of the rainfall hydrology pattern linked to the following rainfall features: rainfall depth, rainfall duration, kinetic energy, average and maximum intensities and erosivity. On average, throughfall events have corresponded to $79.2 \%$ of the gross precipitation. In addition, it has showed to be $36.4 \%$ less erosive than gross precipitation. The advanced rainfall pattern was identified as predominant considering both methodologies for rainfall events individualization.
\end{abstract}

Keywords: Rain kinetic energy; Interaction canopy of eucalyptus-precipitation; Pattern precipitation

\section{Introdução}

O conhecimento das características da chuva permite um planejamento mais seguro de obras e estruturas hidráulicas, bem como a definição de práticas agrícolas adequadas visando à conservação do solo e da água (BAZZANO; ELTZ; CASSOL, 2010). No tocante à erosão hídrica do solo, a chuva é o principal fator de degradação dos solos em regiões tropicais e subtropicais.

\footnotetext{
Engenheiro Florestal, Dr., Professor da Universidade Federal do Tocantins, Campus Gurupi, Rua Badejós, lote 7, s/n, Zona Rural, CEP 77410-070, Gurupi (TO), Brasil. jose.mneto@uft.edu.br (ORCID: 0000-0001-7451-204X)

II Engenheiro Agrícola, Dr., Professor da Universidade Federal de Lavras, Campus universitário, s/n, CEP 37200-000, Lavras (MG), Brasil. crmello@deg.ufla.br (ORCID: 0000-0002-6033-5342)

III Engenheiro Florestal, Dr., Professor da Universidade Federal de Lavras, Campus universitário, s/n, CEP 37200-000, Lavras (MG), Brasil. josemarcio@dcf.ufla.br. (ORCID: 0000-0002-0522-5060)

IV Engenheira Florestal, Drª ., Pós-Doutoranda no Departamento de Ciência do Solo na Universidade Federal de Lavras, Campus universitário, s/n, CEP 37200-000, Lavras (MG), Brasil. danyvguimaraes@hotmail.com (ORCID: 0000-0003-2312-5968)
} 
De acordo com Valvassori e Back (2014), as características de maior influência na erosão hídrica são a intensidade e a duração dos eventos de precipitação.

Os ecossistemas florestais desempenham uma importante função na captação e redistribuição de água da chuva, e, consequentemente, na conservação da água e do solo. Segundo Giglio e Kobiyama (2013), a chuva que cai sobre uma área florestal é naturalmente fracionada em três parcelas: parte dela é interceptada e armazenada pelo dossel e evapora durante ou após o evento de chuva; outra parte cai livremente sobre o solo, sem interferência da vegetação, ou precipita após ser interceptada no interior da floresta; e a terceira parte alcança o solo pelo escoamento nos troncos, após ser interceptada.

O dossel florestal atua na redução das perdas de solo por absorver o impacto da gota de chuva, dissipar sua energia cinética e proporcionar rugosidade à superfície do solo, por meio da deposição de serapilheira, reduzindo assim o efeito erosivo da chuva e favorecendo a infiltração da água no solo. Entretanto, estes efeitos variam com a idade e composição da floresta (SUN et al., 2018). Guimarães et al. (2017) observaram uma redução de 99,98\% da erosão em plantio homogêneo de eucalipto quando comparado a um solo sem cobertura vegetal, corroborando Silva et al. (2016), que encontraram redução da erosão entre 93 e $99 \%$ também em florestas de eucalipto, o que se atribuiu à proteção oferecida pela vegetação contra o efeito da precipitação.

A precipitação interna é um componente que apresenta grande variabilidade espacial dentro da floresta. Sua ordem de grandeza varia entre 70 e $80 \%$ do balanço hídrico anual (RODRIGUES; COSTA, 2009; PYPKER; TARASOFF; KOH, 2012).

Grande parte dos estudos de interceptação e redistribuição da precipitação incidente estão voltados para ecossistemas nativos (CUARTAS et al., 2007; OLIVEIRA et al., 2008; RODRIGUES, 2008; CZIKOWSKY; FITZJARRALD, 2009; MOURA et al., 2009; PYKER; TARASOFF; KOH, 2012; ÁVILA et al., 2014). Giglio e Kobiyama (2013) esclarecem que em se tratando de florestas plantadas, os estudos hidrológicos estão voltados mais frequentemente para os gêneros Eucalyptus e Pinus.

No tocante à caracterização da erosividade da chuva e o padrão da precipitação, os estudos têm sido focados na análise de dados oriundos de estações localizadas a céu aberto, sem nenhuma inferência sobre como o dossel florestal age sobre o evento de precipitação. Entretanto, os processos de interceptação e redistribuição da chuva em um ambiente florestal alteram profundamente as interações chuva-paisagem, afetando os padrões hidrológicos e seus efeitos sobre o solo e o balanço hídrico.

Diante deste fato, o presente estudo foi realizado com o objetivo de caracterizar a precipitação interna de um povoamento de Eucalyptus no município de Lavras, Minas Gerais, associado a padrões hidrológicos que caracterizam os eventos de precipitação.

\section{Materiais e métodos}

O experimento foi conduzido em um povoamento florestal localizado nas dependências do Campus Universitário da Universidade Federal de Lavras (UFLA), município de Lavras, sul de Minas Gerais (Figura 1). A região apresenta como tipo climático uma transição entre CWa e CWb, segundo a classificação climática de Köppen (SPAROVEK; VAN LIER; DOURADO NETO, 2007), apresentando inverno seco e verão chuvoso.

O povoamento com 9 anos de idade ocupa uma área de 1,49 ha formado por clones híbridos do gênero Eucalyptus, em que as espécies que serviram de base genética foram a urophylla e grandis, sendo este híbrido comumente identificado como Urograndis. O espaçamento de plantio foi de $3 \mathrm{~m}$ x $2 \mathrm{~m}$. Atualmente, o povoamento encontra-se com uma população de 1094 indivíduos ha-1, apresentando diâmetro a altura do peito (DAP) médio de $20,6 \mathrm{~cm}$, altura total (HT) média de 28,3 $\mathrm{m}$ e área basal $(\mathrm{AB})$ média de $40,6 \mathrm{~m}^{2} \mathrm{ha}^{-1}$ para o referido povoamento. 


\section{Figura 1 - Localização da área experimental e sensores meteorológicos utilizados.}

Figure 1 - Location of the experimental area and meteorological sensors.

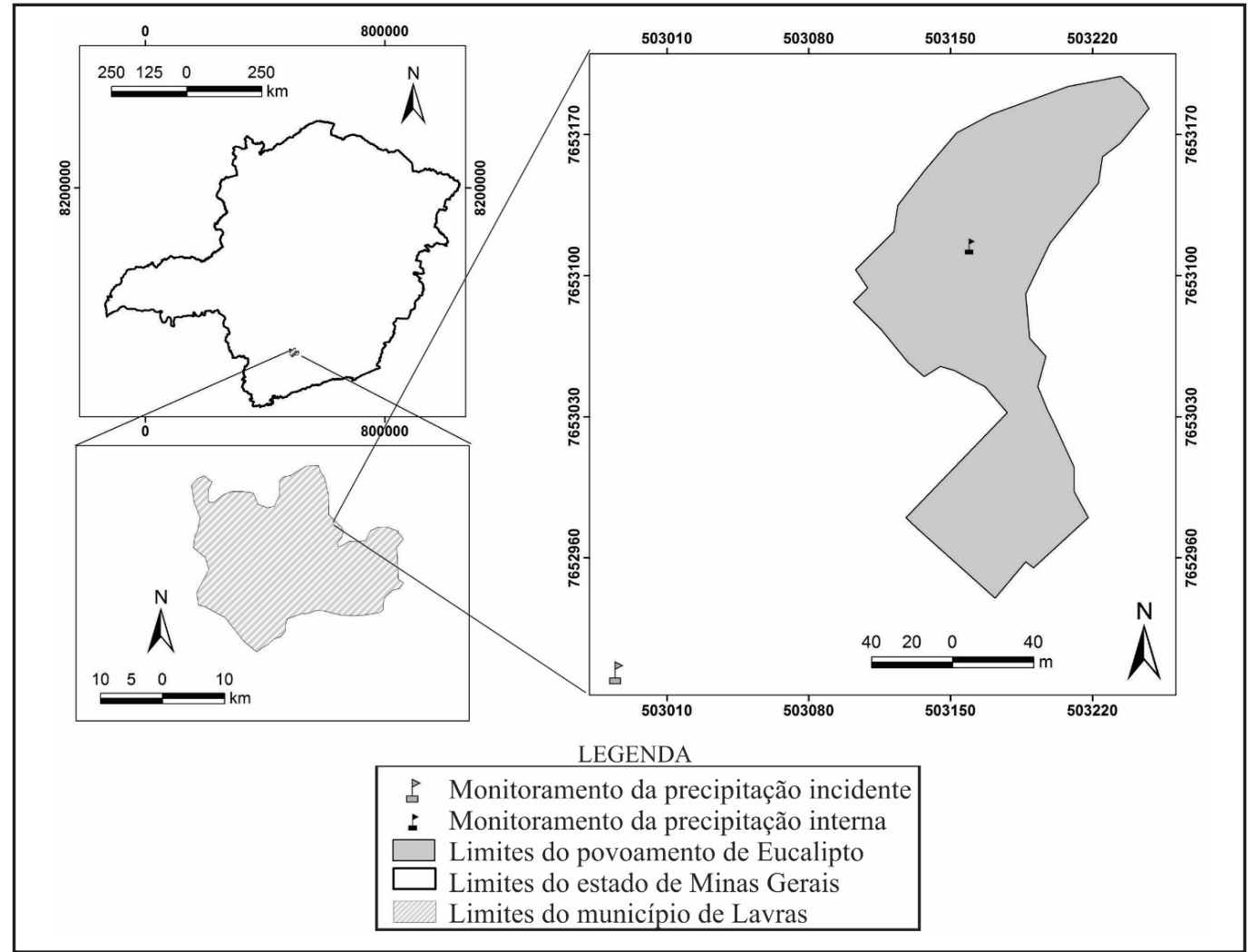

Fonte: Melo Neto et al. (2019)

Para caracterização dos eventos de precipitação foram utilizados dados diários obtidos em duas estações meteorológicas para o período de 1ำ de dezembro de 2013 a 31 de dezembro de 2014. Para determinação da precipitação externa (ou incidente) foram utilizados dados oriundos de pluviogramas registrados no posto de monitoramento do Instituto Nacional de Meteorologia (INMET), localizado a uma distância de 1000 metros do povoamento.

$\mathrm{Na}$ análise da precipitação interna foram utilizados dados obtidos de uma estação meteorológica instalada no centro do povoamento configurada para registrar a lâmina precipitada a cada dez minutos com precisão de $0,2 \mathrm{~mm}$. O percentual da precipitação que atravessa o dossel vegetativo foi obtido através da relação entre os totais mensais da precipitação incidente e a precipitação interna.

Para individualização dos eventos chuvosos foram trabalhadas duas metodologias: a primeira define uma chuva individual como aquela separada de outra por um intervalo mínimo de seis horas (CABEDA, 1976). A segunda metodologia teve como critério um intervalo mínimo entre eventos de três horas, proposta para verificar se há mudanças significativas no comportamento físico da chuva quanto a discretização dos eventos.

Para cada evento individual foi determinado seu tem po de duração, em horas, intensidade média do evento, em mm.h ${ }^{-1}$, e as intensidades máximas em 10, 30, 60 e 120 minutos, todas em $\mathrm{mm} \cdot \mathrm{h}^{-1}$.

A energia cinética de cada evento foi calculada conforme a Equação 1, proposta por Wischmeier e Smith (1978) e adaptada por Foster et al. (1981).

$E c=0,119+0,0873 * \log (I)$

Em que: Ec = energia cinética, em MJ.ha ${ }^{-1} \cdot \mathrm{mm}^{-1} ; \mathrm{I}=$ intensidade média da chuva, em 
$\mathrm{mm} \cdot \mathrm{h}^{-1}$. A energia cinética por incremento de chuva foi obtida conforme a Equação 2:

$$
E c_{i}=E c * L P
$$

Em que: $E c_{i}=$ a energia cinética de cada incremento, em $M J h^{-1} ; \mathrm{LP}=$ lâmina precipitada do incremento de chuva, em $\mathrm{mm}$. A energia cinética do evento de precipitação foi determinada pela soma da energia cinética de cada incremento, conforme Wischmeier e Smith (1978).

A análise do potencial erosivo da precipitação interna e externa foi conduzida com base no índice de erosividade $\mathrm{EI}_{30}$ (Equação 3). Para uma chuva ser considerada erosiva a mesma deve ter como característica uma lâmina total do evento superior a $10 \mathrm{~mm}$ ou energia cinética total do evento maior que 3,6 MJ.ha-1 (DE MARIA, 1994).

$$
E I_{30}=E C_{t} * I_{30}
$$

Em que: $0 \mathrm{EI}_{30}=$ erosividade da chuva $\left(\mathrm{MJ} \cdot \mathrm{mm} \cdot \mathrm{ha}^{-1} \cdot \mathrm{h}^{-1}\right) ; \mathrm{I}_{30}=$ intensidade máxima consecutiva do evento, em 30 minutos. A partir do somatório dos valores de $\mathrm{EI}_{30}$ de cada evento erosivo em cada mês foram obtidas as erosividades mensais.

É proposto também, um procedimento para estimativa do fator de cobertura do solo (C) aplicado na Equação Universal de Perda de Solo (EUPS) a partir da relação entre os índices $\mathrm{EI}_{30}$ internos e externos, conforme Equação 4.

$$
C=1-\frac{E I_{30 i}}{E I_{30 e}}
$$

Em que: $\mathrm{o} \mathrm{EI}_{30 \mathrm{i}}=$ erosividade potencial da precipitação interna; $\mathrm{EI}_{30 \mathrm{e}}=$ erosividade potencial da chuva externa.

Por fim, foram determinados os padrões hidrológicos de cada evento de precipitação interna segundo a classificação proposta por Horner e Jens (1942) que separa os eventos em três classes: avançado - o pico de maior intensidade ocorre antes de $33 \%$ da duração do evento chuvoso, intermediário - o pico de maior intensidade localiza-se entre 33\% e 66\% da duração do evento; e tardio - o pico do evento está após $66 \%$ da duração do mesmo.

Para a análise do padrão hidrológico dos eventos de precipitação interna adotouse como critério uma lâmina mínima de $1,4 \mathrm{~mm}$, pois eventos com lâmina total precipitada inferior a esta, não permitem a classificação devido a presença de múltiplos picos de mesma intensidade ao longo de todo evento ou duração inferior a 30 minutos.

\section{Resultados e discussão}

Durante o período monitorado foram registrados $1232,1 \mathrm{~mm}$ de precipitação externa. Este total foi distribuído em 93 eventos diários, em que a lâmina máxima observada em um único evento foi de $71,2 \mathrm{~mm}$. A precipitação interna apresentou uma lâmina total, no mesmo período, igual a $975,8 \mathrm{~mm}$, correspondendo a $79,2 \%$ da precipitação externa. A maior lâmina observada foi de $52,5 \mathrm{~mm}$.

Balieiro et al. (2007) identificaram um percentual de 78,5\% de precipitação interna para um povoamento de Eucalyptus grandis. Rodrigues e Costa (2009) observaram um valor médio de $80 \%$ da precipitação incidente que consegue ultrapassar o dossel de um povoamento de Eucalyptus grandis. Os valores encontrados neste estudo, portanto, estão muito próximos dos citados, e são explicados pela idade e espaçamento do povoamento (6 $\mathrm{m}^{2}$ e 9 anos), que se apresenta com crescimento estabilizado e bom fechamento de copa, favorecendo assim o processo de interceptação da precipitação incidente.

Na Figura 2 tem-se a distribuição mensal da precipitação externa e interna observada ao longo do período estudado. 
Figura 2 - Precipitação externa e interna observadas no período de 1 de dezembro de 2013 a 31 de dezembro de 2014.

Figure 2 - Gross precipitation and throughfall observed in the period from December 1, 2013 to December 31, 2014.



Fonte: Melo Neto et al. (2019)

O período chuvoso na região sul de Minas Gerais ocorre entre os meses de outubro e março, enquanto que o período seco ocorre entre abril e setembro. Foi observado que $81,1 \%$ do total da precipitação externa ocorre no período chuvoso, restando $18,9 \%$ dos eventos no período seco. Padrão similar foi registrado para a precipitação interna, com percentuais de 80,7 e 19,3 para os períodos chuvoso e seco, respectivamente.

De acordo com Ávila et al. (2014), o processo de redistribuição da água da chuva no ambiente florestal é influenciado pela distribuição temporal dos eventos sendo representado pela sazonalidade climática. Ao discretizar os percentuais de precipitação interna em função da sazonalidade climática verificou-se que o período chuvoso apresenta uma precipitação interna equivalente a $70,3 \%$ da precipitação externa contra $80,3 \%$ para o período seco. No período chuvoso, o dossel permanece úmido por mais tempo permitindo assim alcançar de maneira mais rápida e efetiva a capacidade máxima de armazenamento do mesmo, favorecendo o processo de precipitação interna. Entretanto, na região, as lâminas precipitadas no período seco são concentradas em poucos eventos provocando um efeito similar do período chuvoso com rápida saturação do dossel.

Os 93 eventos diários de precipitação externa registrados no período analisado foram desmembrados em 103 eventos com intervalo mínimo de 6 horas entre eles, dos quais 70 eventos apresentaram lâmina superior a 1,4 mm. Já para a precipitação interna foram contabilizados 61 eventos que atenderam a este critério.

Na Figura 3 são apresentadas as porcentagens dos eventos de precipitação externa e interna classificados de acordo com os padrões hidrológicos para as metodologias de separação da chuva com intervalo mínimo de 6 e 3 horas.

Há um predomínio do padrão avançado em relação aos demais para ambas as precipitações na metodologia de 6 horas. O aumento de eventos classificados com padrão avançado para a precipitação interna pode ser explicado pela influência do dossel florestal. Há um atraso no início do evento internamente quando comparado ao evento externo devido à retenção de água no dossel, provocando uma tendência de aproximação do pico com o terço inicial do evento.

Empregando um intervalo mínimo de 3 horas entre eventos, foram identificados 160 
eventos de precipitação externa dos quais 76 atenderam o critério de lâmina precipitada superior a 1,4 mm, enquanto para a precipitação interna foram identificados 104 eventos dos quais 69 foram classificados.

Figura 3 - Distribuição dos padrões de precipitação externa e interna em um povoamento de eucalipto com intervalo mínimo de 6 (a) e 3 (b) horas.

Figure 3 - Distribution of gross precipitation and throughfall patterns in a eucalyptus stand with a minimum interval of 6 (a) and 3 (b) hours.

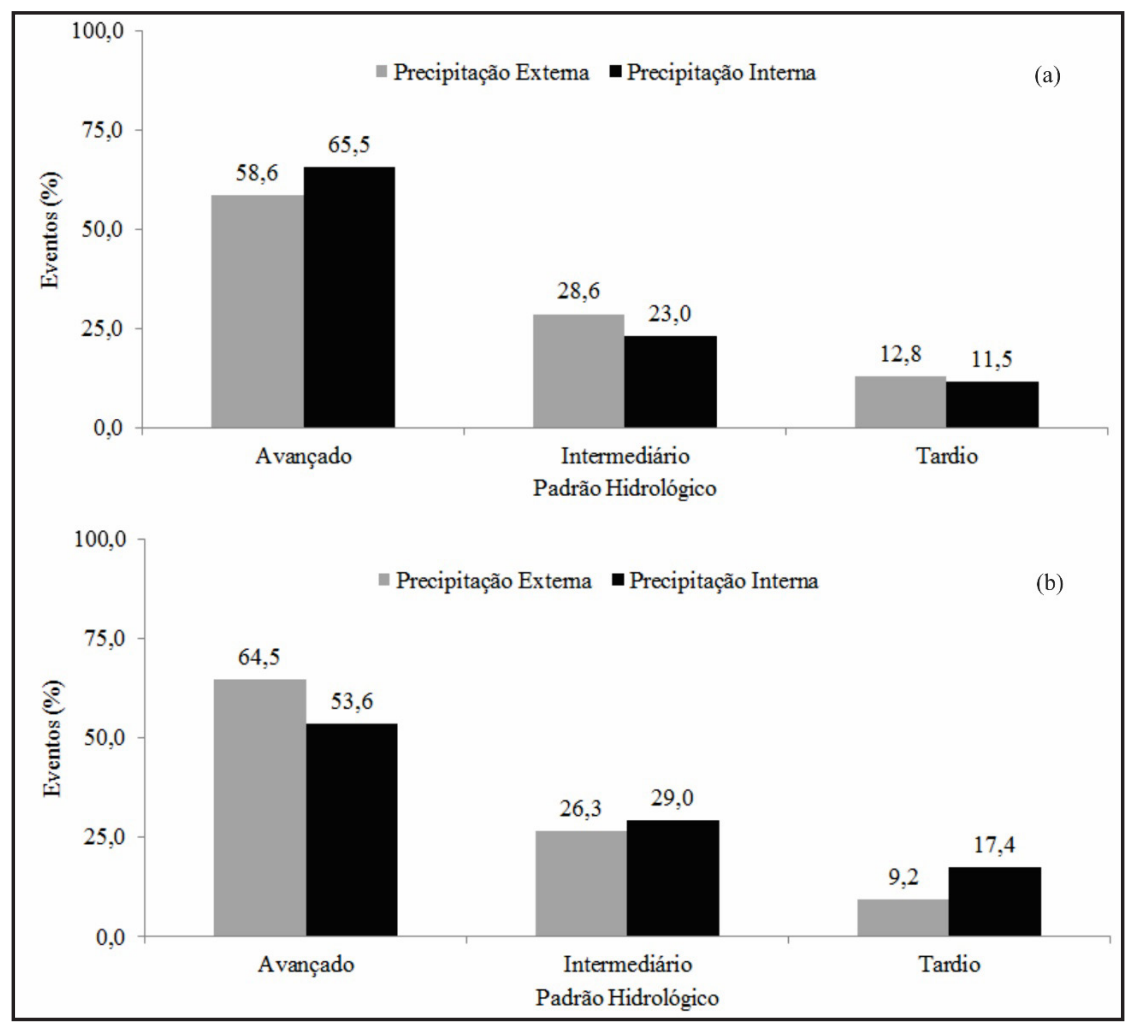

Fonte: Melo Neto et al. (2019)

Com menor intervalo ente os eventos de chuva, o padrão avançado manteve-se dominante, porém, identificou-se uma inversão entre a precipitação externa e interna, onde a incidente apresenta dois terços dos eventos classificados no padrão avançado enquanto que a interna um pouco mais da metade dos eventos enquadrados neste padrão. Destaca-se também o aumento substancial (51\%) dos eventos classificados no padrão tardio para a precipitação interna quando comparado com a separação de 6 horas.

Aquino et al. (2014) estudando os padrões de chuva externa para a região de Lavras, identificaram o padrão avançado como predominante na região, correspondendo a 59\% dos eventos observados. Desta maneira, o padrão da precipitação interna acompanha a dinâmica e o padrão da precipitação externa.

Sob mesmas condições de lâmina precipitada e duração, o padrão avançado tende a ser menos danoso no tocante a erosão, pois o solo encontra-se com menor umidade e a ocorrência do pico no primeiro terço do evento acarretará em menores perdas de solo, uma vez que o solo estará com umidade mais baixa no início do evento, favorecendo a infiltrabilidade. Bazzano, Eltz e Cassol (2010) e Valvassori e Back (2014) identificaram o padrão avançado como menos danoso ao solo quando comparado aos demais padrões de chuva.

$\mathrm{Na}$ Tabela 1 são apresentadas as principais características da precipitação incidente e interna associadas aos eventos separados com intervalo mínimo de 6 horas. 
Tabela 1 - Características da precipitação externa e interna, por padrão de chuva, para eventos individuais com intervalo mínimo de 6 horas.

Table 1 - Characteristics of gross precipitation and throughfall pattern for individual events with a minimum interval of 6 hours.

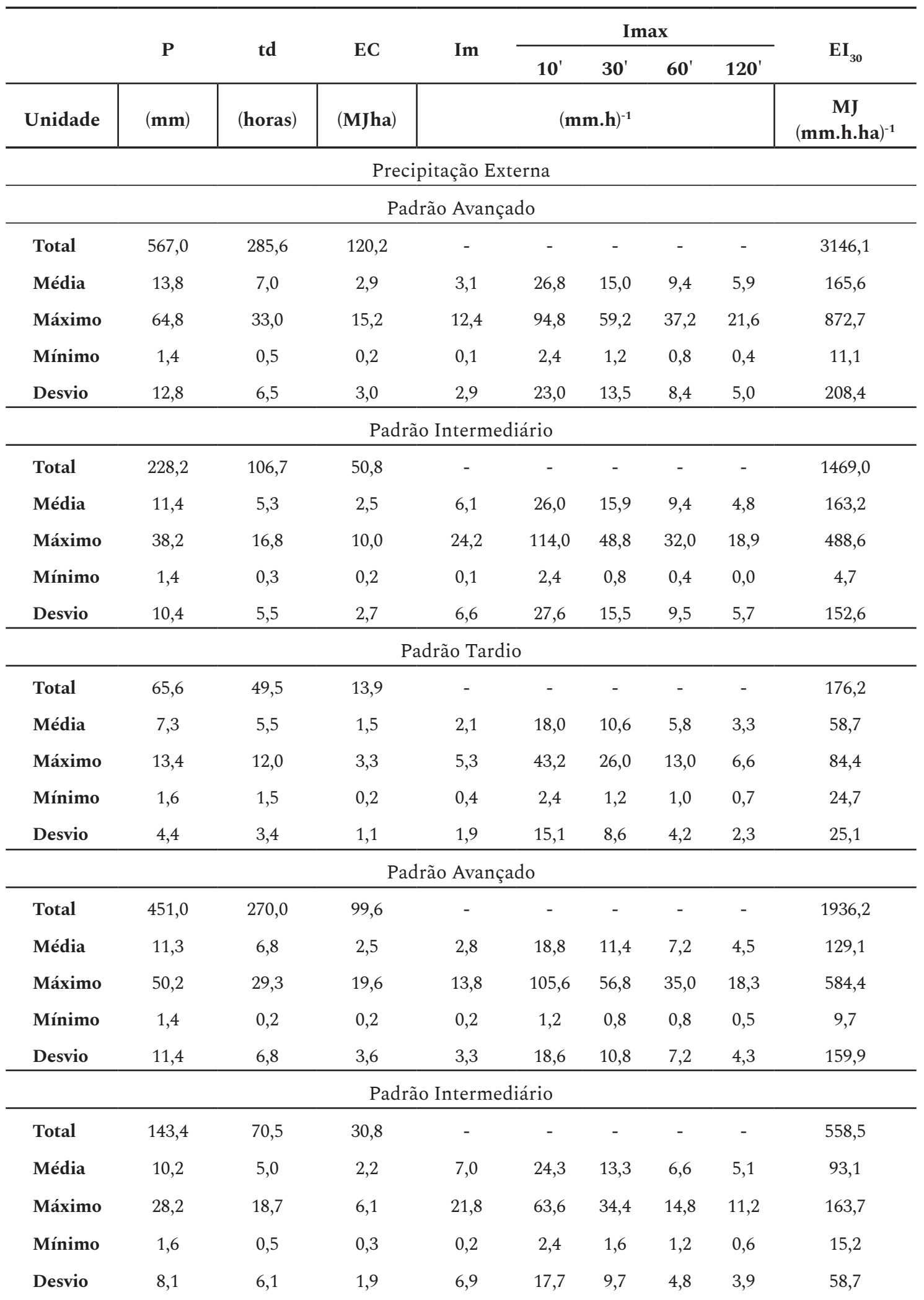

Continua.... 
Tabela 1 - Conclusão...

Table 1 - Conclusion...

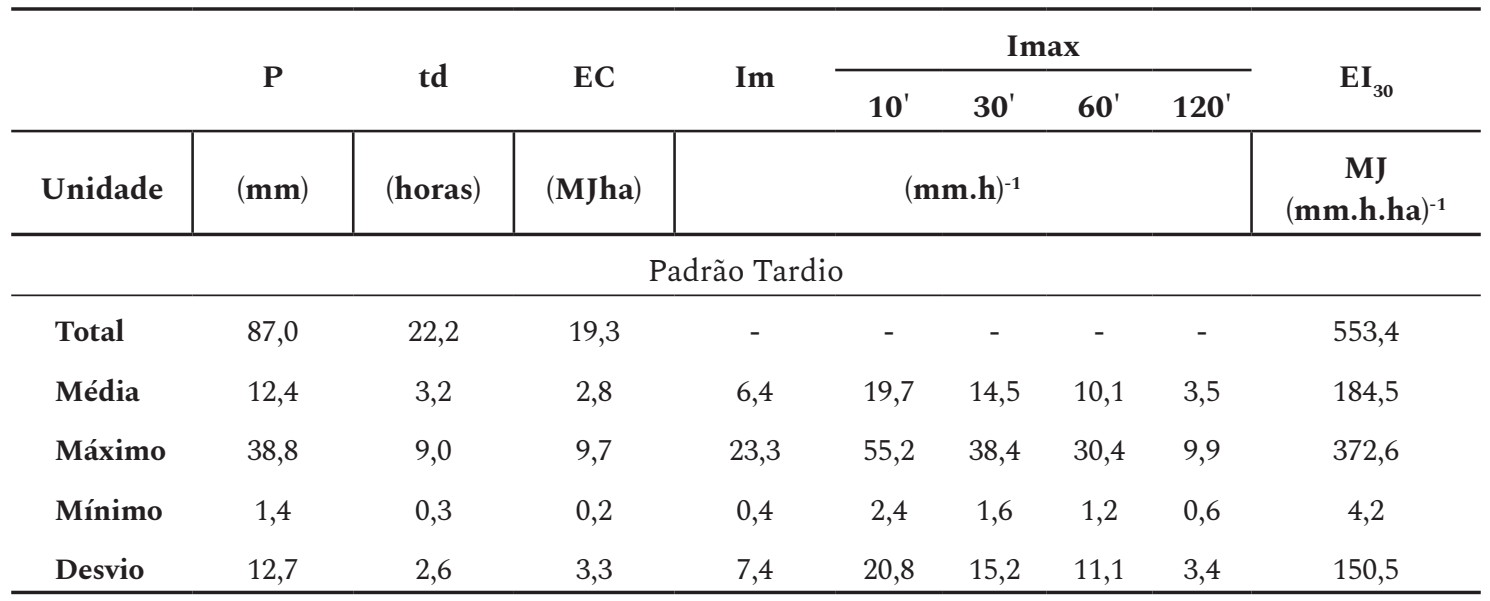

Em que: $\mathrm{P}=$ Precipitação; $\mathrm{td}$ = Tempo de duração do evento; $\mathrm{EC}=$ Energia cinética; $\mathrm{Im}$ = Intensidade média; Imax = Intensidade máxima em um dado intervalo de tempo em minutos; EI30 = Índice de erosividade.

Observa-se, de maneira geral, que todos os padrões de precipitação interna apresentam uma lâmina média precipitada por evento muito próxima, variando entre 10,2 e 12,4 mm, enquanto que a precipitação externa apresenta maior variabilidade em termos médios (7,3 a 13,8 $\mathrm{mm})$. Entretanto, as outras características da chuva analisadas apresentam comportamento distinto entre os padrões.

$\mathrm{Na}$ análise da precipitação interna para o padrão avançado foi encontrado o maior tempo de duração e, consequentemente, menor intensidade média da precipitação. Em contrapartida, os valores de intensidade máxima associados aos intervalos de tempo analisados, bem como a energia cinética do evento foram menores no padrão avançado em relação aos demais, diferente do comportamento observado para a precipitação externa.

Na Figura 4 são apresentadas as erosividades totais mensais para a precipitação externa e interna, bem como os valores calculados para o fator de cobertura proposto, com base na atenuação do efeito erosivo da chuva propriamente dito.

Figura 4 - Erosividade total mensal externa e interna e fator de cobertura do solo.

Figure 4 - External and internal total monthly erosivity and land cover factor.

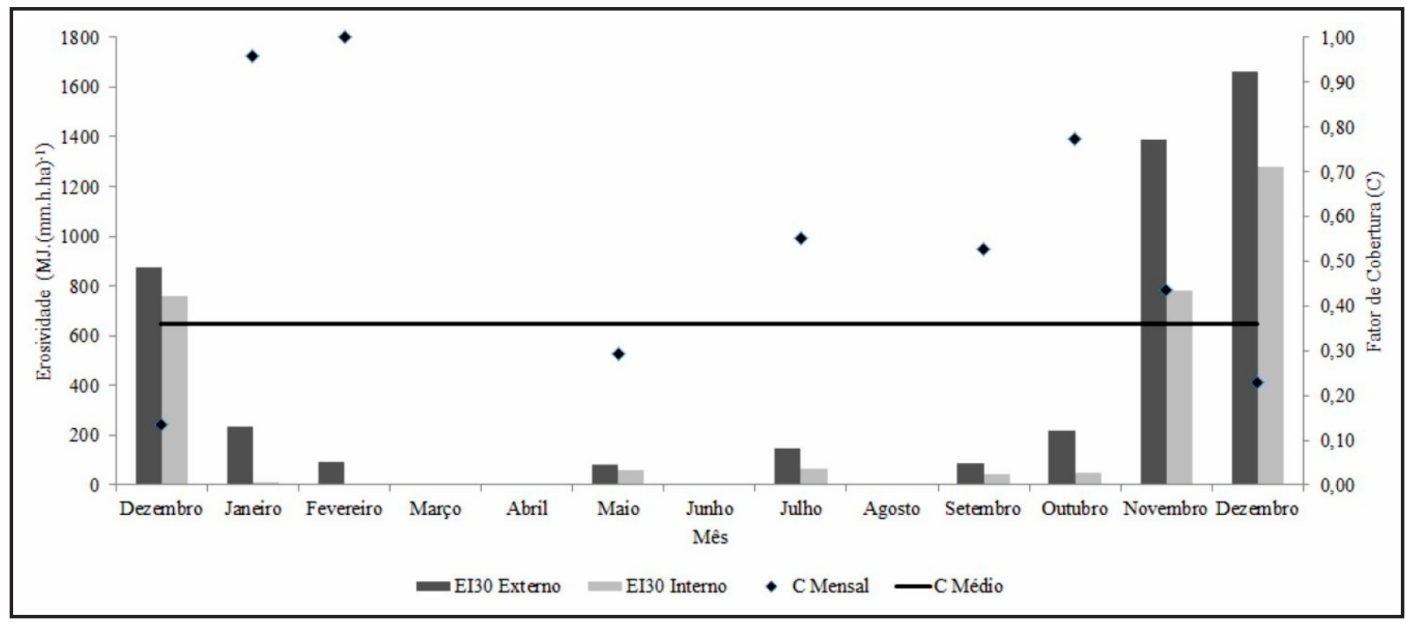

Fonte: Melo Neto et al. (2019) 
Do total observado de erosividade, $93,3 \%$ foi provocado pela precipitação externa no período chuvoso. Comportamento similar também foi observado para a erosividade provocada pela precipitação interna $(94,5 \%)$. Os dados encontrados para a precipitação interna apresentamse, em termos totais, $36,4 \%$ menores que os observados para a precipitação externa.

Segundo classificação proposta por Carvalho (2008), a erosividade externa, no período de análise, pode ser classificada como média, apresentando um valor total anual de 3521,6 MJ.mm. (h.ha) $)^{-1}$, enquanto a erosividade provocada pela precipitação interna enquadra-se como baixa $\left.(2029,0 \text { MJ.mm.(h.ha) })^{-1}\right)$.

Os resultados encontrados para a precipitação interna reforçam algumas evidências encontradas em estudos de precipitação externa (BAZZANO; ELTZ; CASSOL, 2010; AQUINO et al., 2014; VALVASSORI; BACK, 2014) de que o padrão avançado é menos danoso ao solo. Ao correlacionar proporcionalmente a lâmina total precipitada ao $\mathrm{EI}_{30}$, o padrão tardio apresentouse como mais danoso ao solo, com erosividade de $2868,8 \mathrm{MJ} \cdot \mathrm{mm}^{-1} \cdot \mathrm{h}^{-1} \cdot \mathrm{ha}^{-1}$, seguido do padrão avançado $\left(1936,2 \mathrm{MJ} \cdot \mathrm{mm}^{-1} \cdot \mathrm{h}^{-1} \cdot \mathrm{ha}^{-1}\right)$ e intermediário $\left(1756,5 \mathrm{MJ} \cdot \mathrm{mm}^{-1} \cdot \mathrm{h}^{-1} \cdot \mathrm{ha}^{-1}\right)$.

Originalmente, o parâmetro fator de cobertura do solo (C) da EUPS é determinado em função da relação entre a perda de solo observada em área descoberta com a perda de solo na área com uma cobertura específica. O monitoramento da perda de solo é trabalhoso e altamente variável devido às interações com os diversos componentes da paisagem.

A metodologia aqui proposta para ambientes florestais busca simplificar a estimativa deste parâmetro tratando, de forma indireta, os efeitos da cobertura na redistribuição da precipitação externa para o solo utilizando somente dados de precipitação que podem ser obtidos com o emprego de estações meteorológicas automáticas.

O valor médio do fator $C$ encontrado foi de 0,36 , indicando uma boa cobertura do solo. Martins et al. (2010) encontraram um valor de 0,30 para o fator $C$ avaliando um povoamento de eucalipto com 7 anos de idade aplicando a metodologia proposta por Wischmeier e Smith (1978).

Na Tabela 2 são apresentadas as principais características da precipitação externa e interna associadas aos eventos separados com intervalo mínimo de 3 horas.

\section{Tabela 2 - Características da precipitação externa e interna por padrão de chuva para eventos individuais com intervalo mínimo de 3 horas.}

Table 2 - Characteristics of gross precipitation and throughfall pattern for individual events with a minimum interval of 3 hours.

\begin{tabular}{|c|c|c|c|c|c|c|c|c|}
\hline & \multirow{2}{*}{$\mathbf{P}$} & \multirow{2}{*}{ td } & \multirow{2}{*}{ EC } & \multirow{2}{*}{ Im } & \multicolumn{4}{|c|}{ Imax } \\
\hline & & & & & $10^{\prime}$ & 30' & $60^{\prime}$ & 120' \\
\hline Unidade & $(\mathbf{m m})$ & (horas) & (MJ.ha) & & & $\left.\mathbf{m} \cdot \mathbf{h}^{-1}\right)$ & & \\
\hline \multicolumn{9}{|c|}{ Precipitação Externa } \\
\hline \multicolumn{9}{|c|}{ Padrão Avançado } \\
\hline Total & 607,8 & 210,6 & 131,0 & - & - & - & - & - \\
\hline Média & 12,4 & 4,3 & 2,7 & 4,1 & 26,0 & 14,6 & 9,1 & 6,4 \\
\hline Máximo & 64,8 & 23,3 & 15,2 & 15,0 & 94,8 & 59,2 & 37,2 & 21,6 \\
\hline Mínimo & 1,4 & 0,5 & 0,2 & 0,3 & 1,2 & 0,4 & 0,4 & 0,4 \\
\hline Desvio & 12,1 & 4,3 & 2,8 & 3,5 & 22,2 & 13,1 & 8,3 & 5,1 \\
\hline \multicolumn{9}{|c|}{ Padrão Intermediário } \\
\hline Total & 199,2 & 63,0 & 44,6 & - & - & - & - & - \\
\hline
\end{tabular}


Tabela 2 - Conclusão...

Table 2 - Conclusion...

\begin{tabular}{|c|c|c|c|c|c|c|c|c|}
\hline & \multirow{2}{*}{$\mathbf{P}$} & \multirow{2}{*}{ td } & \multirow{2}{*}{ EC } & \multirow{2}{*}{ Im } & \multicolumn{4}{|c|}{ Imax } \\
\hline & & & & & 10 ' & $30^{\prime}$ & $60^{\prime}$ & $120^{\prime}$ \\
\hline Unidade & $(\mathbf{m m})$ & (horas) & (MJ.ha) & & & $\left.\mathbf{m} \cdot \mathbf{h}^{-1}\right)$ & & \\
\hline \multicolumn{9}{|c|}{ Precipitação Externa } \\
\hline \multicolumn{9}{|c|}{ Padrão Intermediário } \\
\hline Média & 10,0 & 3,2 & 2,2 & 6,5 & 24,2 & 14,9 & 8,9 & 4,9 \\
\hline Máximo & 38,2 & 10,7 & 10,0 & 24,2 & 114,0 & 48,8 & 32,0 & 18,9 \\
\hline Mínimo & 1,4 & 0,3 & 0,2 & 0,1 & 2,4 & 0,8 & 0,4 & 0,3 \\
\hline Desvio & 10,0 & 3,1 & 2,6 & 6,6 & 28,0 & 15,9 & 9,7 & 5,8 \\
\hline \multicolumn{9}{|c|}{ Padrão Tardio } \\
\hline Total & 39,0 & 17,3 & 7,8 & - & - & - & - & - \\
\hline Média & 5,6 & 2,5 & 1,1 & 4,7 & 12,9 & 7,3 & 4,3 & 2,5 \\
\hline Máximo & 12,0 & 4,3 & 2,5 & 16,8 & 22,8 & 15,6 & 7,8 & 5,3 \\
\hline Mínimo & 1,6 & 0,2 & 0,2 & 0,4 & 2,4 & 1,2 & 1,0 & 0,7 \\
\hline Desvio & 3,8 & 1,2 & 0,8 & 5,3 & 8,0 & 5,1 & 2,7 & 1,9 \\
\hline \multicolumn{9}{|c|}{ Precipitação Interna } \\
\hline \multicolumn{9}{|c|}{ Padrão Avançado } \\
\hline Total & 409,2 & 177,9 & 83,9 & - & - & - & - & - \\
\hline Média & 11,1 & 4,8 & 2,3 & 3,3 & 19,9 & 11,9 & 7,7 & 4,9 \\
\hline Máximo & 50,2 & 23,7 & 10,7 & 13,2 & 105,6 & 56,8 & 35,0 & 18,3 \\
\hline Mínimo & 1,4 & 0,2 & 0,2 & 0,3 & 1,2 & 0,8 & 0,8 & 0,5 \\
\hline Desvio & 11,0 & 5,0 & 2,5 & 3,1 & 19,8 & 11,2 & 7,6 & 4,6 \\
\hline \multicolumn{9}{|c|}{ Padrão Intermediário } \\
\hline Total & 146,4 & 30,7 & 31,8 & - & - & - & - & - \\
\hline Média & 7,3 & 1,5 & 1,6 & 7,8 & 19,9 & 11,5 & 5,5 & 4,2 \\
\hline Máximo & 23,4 & 7,3 & 5,4 & 21,8 & 63,6 & 34,4 & 12,8 & 11,2 \\
\hline Mínimo & 1,6 & 0,3 & 0,2 & 0,8 & 2,4 & 1,6 & 1,0 & 0,6 \\
\hline Desvio & 5,4 & 1,7 & 1,3 & 6,0 & 14,2 & 8,0 & 3,4 & 3,7 \\
\hline \multicolumn{9}{|c|}{ Padrão Tardio } \\
\hline Total & 118,8 & 46,2 & 24,8 & - & - & - & - & - \\
\hline Média & 9,9 & 3,8 & 2,1 & 4,2 & 14,5 & 9,9 & 6,8 & 2,6 \\
\hline Máximo & 38,8 & 12,7 & 9,7 & 23,3 & 55,2 & 38,4 & 30,4 & 9,9 \\
\hline Mínimo & 1,4 & 0,3 & 0,2 & 0,4 & 2,4 & 1,2 & 1,0 & 0,6 \\
\hline Desvio & 11,3 & 3,3 & 2,8 & 6,3 & 17,3 & 12,6 & 9,1 & 2,7 \\
\hline
\end{tabular}

Em que: $\mathrm{P}=$ Precipitação interna; $\mathrm{td}$ = Tempo de duração do evento; $\mathrm{EC}$ = Energia cinética; $\mathrm{Im}$ = Intensidade média; Imax = Intensidade máxima em um dado intervalo de tempo em minutos. 
Ao aumentar a discretização da precipitação, externa e interna, com um intervalo menor para individualização dos eventos, não foram encontradas diferenças significativas quando comparados aos dados da discretização com intervalo mínimo de 6 horas.

Com esta discretização dos eventos foi observado comportamento similar entre as precipitações incidente e interna para todos os padrões hidrológicos de chuva analisados. $\mathrm{O}$ padrão avançado apresentou maior tempo de duração e menor intensidade, em termos médios. Identificou-se, portanto, uma aproximação entre os eventos com padrão intermediário e tardio em termos de totais precipitados. O padrão tardio apresentou os menores valores, em termos médios, de intensidade máxima associada aos vários tempos de duração analisados.

\section{Conclusão}

A precipitação interna total registrada em um povoamento adulto de Eucalyptus correspondeu a $79,2 \%$ da precipitação incidente. Ao avaliar o efeito sazonal, a precipitação interna apresenta um comportamento similar entre os períodos seco $(70,3 \%)$ e chuvoso $(80,3 \%)$.

A precipitação interna mostrou-se $36,4 \%$ menos erosiva que a precipitação incidente, onde o padrão avançado foi identificado como predominante na série analisada em ambas as metodologias de individualização dos eventos, padrão este que apresenta as características de chuva menos danosas para a conservação da água e solo na paisagem estudada. $O$ valor médio encontrado para o fator de cobertura do solo (C) proposto foi de 0,36 .

Não foram identificadas diferenças marcantes nos resultados obtidos com a discretização dos eventos de precipitação, incidente e interna, com intervalo mínimo de 6 e 3 horas, assim a escolha entre ambas as metodologias fica em função da base de dados disponível.

\section{Referências}

AQUINO, R. F. et al. Soil losses from typic Cambisols and Red Latosol as related to three erosive rainfall patterns. Revista Brasileira de Ciência do Solo, Viçosa, MG, v. 37, p. 213-220, 2014.

ÁVILA, L. F. et al. Partição da precipitação pluvial em uma microbacia hidrográfica ocupada por Mata Atlântica na Serra da Mantiqueira, MG. Ciência Florestal, Santa Maria, v. 24, n. 3, p. 583595, jul./set. 2014.

BALIEIRO, F. C. et al. Evaluation of the throughfall and stemflow nutrient contents in mixed and pure plantations of Acacia mangium, Pseudosamenea guachapele and Eucalyptus grandis. Revista Árvore, Viçosa, MG, v. 31, n. 2, p. 339-346, 2007.

BAZZANO, M. G. P.; ELTZ, F. L. F.; CASSOL, E. A. Erosividade e características hidrológicas das chuvas de Rio Grande (RS). Revista Brasileira de Ciência do Solo, Viçosa, MG, v. 34, p. 235$244,2010$.

CABEDA, M. S. V. Computation of storm EI values. West Lafayette: Purdue University, 1976. 6 p. CARVALHO, N. O. Hidrossedimentologia prática. 2. ed. [S. l.]: Interciência, 2008. 600 p.

CUARTAS, L. A. et al. Bpristine rainforest in Central Amazonia: marked differences between normal and dry years. Agricultural and Forest Meteorology, Amsterdam, v. 145, n. 1-2, p. 69-83, 2007.

CZIKOWSKY, M. J.; FITZJARRALD, D. R. Detecting rainfall interception in an Amazonian rain forest with eddy flux measurements. Journal of Hydrology, Amsterdam, v. 377, p. 92-105, 2009.

DE MARIA, I. C. Cálculo da erosividade da chuva. In: LOMBARDI NETO, F. et al. Manual de programas de processamento de dados de campo e de laboratório para fins de experimentação em conservação do solo. Campinas: IAC; SCS, 1994. 
FOSTER, G. R. et al. Conversion of the universal soil loss equation to SI metric units. Journal of Soil Water Conservation, [s. l.], v. 36, p. 355-359, 1981.

GIGLIO, J. N.; KOBIYAMA, M. Interceptação da chuva: uma revisão com ênfase n monitoramento em florestas Brasileiras. Revista Brasileira de Recursos Hídricos, Porto Alegre, v. 18, n. 2, p. 297-317, abr./jun. 2013.

GUIMARÃES, D. V. et al. Water erosion associated with rainfall patterns in the extreme South of Bahia in eucalyptus post-planting. Semina: Ciências Agrárias, Londrina, v. 38, n. 4, p. 24632478, 2017.

HORNER, W. W.; JENS, S. W. Surface runoff determination from rainfall without using coefficients. Transactions of ASAE, [s. l.], v. 107, p. 1039-1117, 1942.

MARTINS, S. G. et al. Fator de cobertura e manejo do solo e perdas de solo e água em cultivo de eucalipto e em mata Atlântica nos tabuleiros costeiros do estado do Espírito Santo. Scientia Forestalis, Piracicaba, v. 38, n. 87, p. 517-526, 2010.

MOURA, A. E. S. S. et al. Interceptação das Chuvas em um Fragmento de Floresta da Mata Atlântica na Bacia do Prata, Recife, PE. Revista Árvore, Viçosa, MG, v. 33, n. 3, p. 461-469, 2009.

OLIVEIRA, L. L. et al. Precipitação efetiva e interceptação em Caxiamã, na Amazônia Oriental. Acta Amazonica, Manaus, v. 38, n. 4, p. 723-732, 2008.

PYPKER, T. G.; TARASOFF, C. S.; KOH, H. Assessing the eficacy of two indirect methods for quantifying canopy variables associated with the interception loss of rainfall in temperate hardwood forests. Open Journal of Modern Hydrology, [s. l.], v. 2, p. 29-40, 2012.

RODRIGUES, V. A. Redistribuição da precipitação em seringueiras. Irriga, Botucatu, v. 13, n. 4, p. 566-575, 2008.

RODRIGUES, V. A.; COSTA, P. N. Precipitação efetiva e interceptação das chuvas em povoamento de eucalipto. Revista Brasileira de Engenharia de Biossistemas, Campinas, v. 3, n. 1, p. 77-86, jan./abr. 2009.

SILVA, B. P. C. et al. Soil and water losses in eucalyptus plantation and natural forest and determination of the USLE factors at a pilot sub-basin in Rio Grande do Sul, Brazil. Ciência e Agrotecnologia, Lavras, v. 40, n. 4, p. 432-442, 2016.

SPAROVECK, G.; VAN LIER, Q. J.; DOURADO NETO, D. Computer assisted Köppen climate classification: a case of study for Brazil. International Journal of Climatology, Reading, v. 27, n. 2, p. 257-266, 2007.

SUN, D. et al. Soil erosion and water retention varies with plantation type and age. Forest Ecology and Management, Amsterdam, v. 422, p. 1-10, 2018.

VALVASSORI, M. L.; BACK, A. J. Caracterização das chuvas erosivas em Urussanga, SC, com relação ao padrão de distribuição temporal. Revista Brasileira de Ciência do Solo, Viçosa, MG, v. 38, p. 1020-1027, 2014.

WISCHMEIER, W. H.; SMITH, D. D. Predicting rainfall erosion losses: a guide to conservation planning. Washington: USDA, 1978. 58 p. 